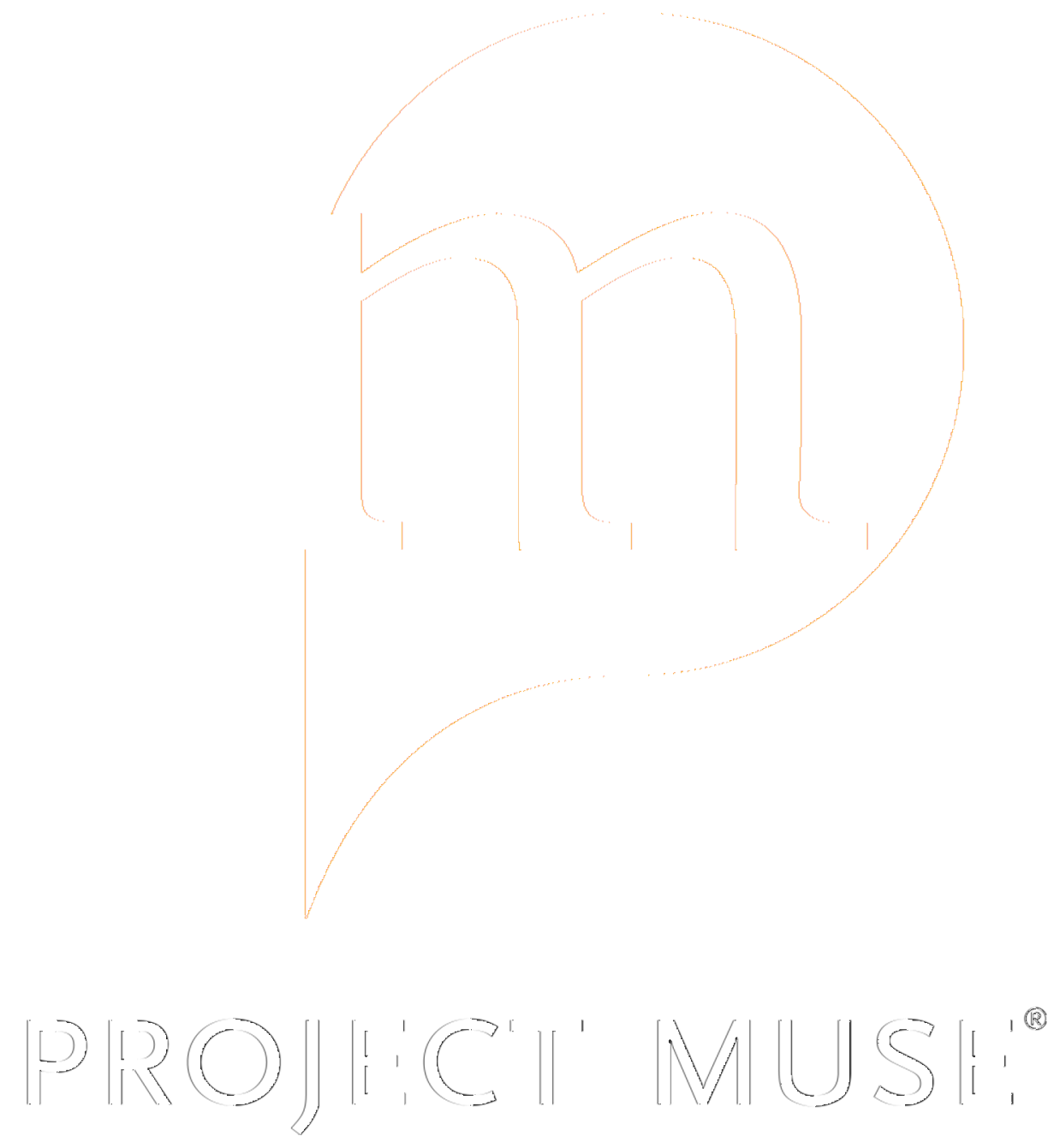

Access provided by University of Exeter (15 Dec 2015 08:48 GMT) 


\title{
FROM DISPOSABILITY TO RECYCLING: WILLIAM FAULKNER AND THE NEW POLITICS OF REWRITING IN JESMYN WARD'S SALVAGE THE BONES
}

\author{
SINÉAD MOYNIHAN
}

[T] he writer, as I say, never forgets [what he has read], he stores it away-he has no morals - and when he needs it, he reaches around and drags it out, and if it doesn't quite fit what he wants to say he'll probably change it just a little.

- William Faulkner (qtd. in Gwynn and Blotner 251)

In the early stages of Jesmyn Ward's Salvage the Bones (2011), the fifteen-year-old narrator, Esch, recalls reading William Faulkner's As I Lay Dying (1930) as a summer assignment between ninth and tenth grades. She "made an A because [she] answered the hardest question right: Why does the young boy think his mother is a fish?" (Ward 7, emphasis in original). As the novel progresses, it becomes clear that this teenage girl, whose mother died in childbirth seven years previously, must understand and identify with Faulkner's motherless Vardaman at the most basic level. More generally, it also becomes evident that Salvage the Bones is deeply and self-consciously indebted to the work of Ward's fellow Mississippian writer, William Faulkner. Salvage the Bones is the tale of a poor African American family, the Batistes, living on the Mississippi bayou: Esch, her older brothers, Randall and Skeetah, younger brother, Junior, and their widowed father, Claude. It charts the days immediately before, during, and after Hurricane Katrina struck in August 2005. Beyond making superficial connections between Katrina and the weather event alternately called a "storm" and a "cyclone" in As I Lay Dying (Faulkner 39, 37, 61), how are we to understand this young African American woman writer's engagement with Faulkner's novel in Salvage the Bones?

Emphasizing both formal and thematic convergences with and divergences from As I Lay Dying, this essay argues that, in Salvage the Bones, Ward engages in a new, more politicized version of what Peter Widdowson terms 
"re-visionary fiction" (496), a form that cannot easily be categorized in terms of existing models of parody, revision, rewriting, and writing back to the center most often associated with feminism, postcolonialism, and/or postmodernism. While classic rewritings such as Jean Rhys's Wide Sargasso Sea (1966) and J. M. Coetzee's Foe (1986) have received much critical attention for revealing the extent to which Charlotte Bronte's Jane Eyre (1847) and Daniel Defoe's Robinson Crusoe (1719) silenced their colonial subjects, several scholars have pointed out that re-visionary fiction is a profoundly limited form of critique. Its political possibilities are weakened in two ways: first, because its assault on the canonical text relies on a reader's familiarity with that text, rewriting effectively reifies the authority of the canon at the same time that it attempts to undermine it; second, because it privileges historical text over social reality, it can make little or no comment on contemporary racial, class, and gender inequalities.

In Salvage the Bones, Ward revises this tradition of rewriting and, by extension, addresses the above two limitations. Revision acknowledges literary longevity and durability: a canonical text is targeted for rewriting in part because it has played such an influential and enduring role in the national and/ or global literary imaginary. In Ward's novel, however, As I Lay Dying is the vehicle for, rather than the target of, her critique. Salvage the Bones is populated by poor, African American characters that are subject to "the biopolitics of disposability" that has resulted from neoliberal and neoconservative incursions on the US welfare state over the past thirty years, the effects of which were made manifest by Hurricane Katrina (Giroux 175). Capitalizing on the canonical status of Faulkner's earlier text, Ward strategically invokes As I Lay Dying in order to confer on the characters in Salvage the Bones, through their association with Faulkner's, a dignity denied them in the post-Katrina moment. By appealing to Faulkner's canonical text, and adapting it to the contemporary context of Hurricane Katrina, Ward challenges conservative assaults on the African American family (and, in particular, on the African American single mother) and asserts the resistance of this particular African American family to neoliberal discourses that would consign them to the category of "waste" (Giroux 187). In so doing, Ward engages in an act of rewriting that places the (social) present on an equal footing with the (literary) past. Ward thus moves towards a more politically engaged model of rewriting that can more accurately be called "recycling," a term with connotations of resolute social engagement and looking outward and forward, as opposed to the potentially solipsistic and retrospective textual worlds with which rewriting tends to be concerned. The recycling of Faulkner's novel in Salvage the Bones, through its combined social and textual emphases, provides a means of revivifying revisionary fiction as a literary-political enterprise.

Before moving on to unpack in more detail the politics of recycling and "the biopolitics of disposability," it is necessary first to establish that 
Salvage the Bones resembles As I Lay Dying sufficiently to describe it as a rewriting thereof. Both texts focus on poor, rural, male-dominated families in Mississippi, in which the absent mother is a conspicuous ghostly presence and in which rising floodwaters generate the texts' key dramatic tensions. Moreover, both novels feature pregnant teenagers, Dewey Dell and Esch, who struggle to come to terms with impending motherhood in the context of socioeconomic and personal circumstances that profoundly limit their opportunities. Faulkner's text reverberates in Ward's through characterization, as well as through motifs (floods and storms; trees) and themes (sexuality and reproduction; maternity; rural poverty). ${ }^{1}$ Ward draws upon these characters, motifs, and themes because they provide touchstones for social anxieties and fears that had been circulating since at least the early 1980s and that achieved renewed discursive power in post-Katrina discourse: (black) teenage sexuality; (black) single motherhood; "lightly parented adolescent [black] males" (Will); in short, the pathologizing of the African American family. However, Ward also departs from As I Lay Dying in significant ways: the poor white family in As I Lay Dying becomes a poor black family in Salvage the Bones; there are five Bundren siblings to four Batistes; and the characters in the two novels do not easily map on to one another. Furthermore, Ward narrows Faulkner's fifteen narrators down to just one, thus privileging Esch's voice and experience. In all of these instances, Ward's radical repurposing of Faulkner's novel constitutes a counter-discursive gesture on her part, a challenge to mythologies surrounding the African American family that were circulating when Salvage the Bones was composed.

\section{From Rewriting to Recycling}

The literary-political enterprise that is rewriting, whether in its postcolonial or feminist manifestations, is deeply intertwined with the rise of postmodernist philosophies and aesthetic strategies in the second half of the twentieth century. In Linda Hutcheon's famous configuration, postmodern art is often characterized by "a critical revisiting, an ironic dialogue with the past of both art and society, a recalling of a critically shared vocabulary." This engagement with the past is "always a critical reworking, never a nostalgic 'return"" (Poetics 4). Scholarly disagreements over the political possibilities of postmodernism provide one way of thinking about the ambivalence of rewriting as a literary-political project. For Hutcheon, postmodernism can be "critical": implicit in postmodern, postcolonial, and feminist reconfigurations of canonical texts, then, is the motivation to decenter historically dominant voices and "to counter a tradition of silence and alleged misrepresentation" (Plate 394). Such models presuppose a desire to "denaturalise the original" in order to restore "a voice, a history and an identity to those hitherto exploited, marginalized and silenced by dominant interests and ideologies" (Widdowson 503, 505-06). However, Hutcheon elsewhere notes that because postmodernism 
"juxtaposes and gives equal value to the self-reflexive and the historically grounded," its politics is "ultimately compromised"; it can only ever engage in a kind of "complicitous [sic] critique" (Politics 2). Rewriting, too, is complicit in maintaining the canonicity of the prior text at the same time that it attempts to challenge it. As Liedeke Plate summarizes, the "mutual dependency of canonical work and rewriting is a complex relationship" (396): because the rewrite is ultimately validated by the original text, rewriting may well be "an inherently conservative genre" (Plate 397; Sanders 9). In other words, even if feminist and/or postcolonial re-visionary fiction institutes a "rupture" (Moraru 9) with the prior text in its bid to assert oppositional meanings, it is still wholly dependent on that earlier text, a reliance that may reify that which it seeks to decenter and deconstruct. Ward, too, draws attention to- and thus perpetuates - the cultural capital of Faulkner's original text. However, Salvage the Bones is not characterized by an impulse to decenter and deconstruct but, rather, to radically repurpose Faulkner's original.

According to Fredric Jameson, postmodernism empties out the political possibilities of particular cultural and aesthetic strategies. While, for Hutcheon, postmodern parody is underwritten by a critical edge, Jameson argues that postmodernist art employs not parody but pastiche, which entails "a neutral practice of...mimicry, without any of parody's ulterior motives, amputated of the satiric impulse, devoid of laughter" (17). Somewhat similarly, Jean Baudrillard finds that postmodern culture is so moribund that "the human race is beginning to produce itself as waste-product, to carry out this work of waste disposal on itself" (78). By producing "highly centralized structures, highly developed urban, industrial and technical systems, by remorselessly condensing down programmes, functions and models, we are transforming all the rest into waste, residues, useless relics" (78). Because of his indebtedness to Jamesonian and Baudrillardian analyses of postmodern culture, "recycling" is a turn of phrase that Christian Moraru rejects in his study of rewriting because it smacks of "impotent rumination, routine, superficiality, worthlessness, refuse" and "dealing in the waste of our "excremental culture" (7). For him, it signifies those tendencies of postmodernism identified by Jameson and Baudrillard that are at best apolitical and at worst deeply reactionary and conservative. However, his preferred term is much more problematic. The form of rewriting he valorizes is "a writerly repetition turning out a salient, textual, and political surplus; a return in the financial sense, so to speak" (14). It is clear what Moraru is getting at here: he wants to challenge constructions of rewriting that would frame it as derivative or plagiaristic by emphasizing the extent to which it creates "a notable, formal surplus, and an ideological, revisionary difference to boot" (7). The capitalistic language is unfortunate, however, because it subjects re-visionary fiction to a kind of marketplace logic that burdens it with the production of an excess of textual meanings. By contrast, framing Ward's enterprise as "recycling" accomplishes much more 
important ideological work: by "recycling" a canonical text-a work that is always already associated with literary worth and value - it calls into question all that is framed as "waste" (including human beings); second, by "recycling" As I Lay Dying, it paves the way for a form of rewriting that is more engaged with contemporary social realities than has previously been the case.

The form of rewriting Ward undertakes in Salvage the Bones, then, exposes the fault lines of debates on the political possibilities of postmodern rewriting. Ward's project forces readers to destabilize their assumptions about the decentering and deconstructive aspects of rewriting and, by extension, the relationship between canonical text and rewrite. While Ward does rework aspects of Faulkner's novel and these revisions are significant, there is little evidence in Salvage the Bones that Ward's text is another of "those southern books that might be subtitled "Arguments with Faulkner"' (Gray 11). This is despite Ward's own claim, in an interview with the Guardian, that she encountered the Creole characters in Faulkner's Absalom, Absalom! (1936) and thought: "I have problems with the ways these characters are coming alive on the page. They aren't coming alive like the [white] characters; these characters feel flat to me" (Brockes). Significantly, Ward does not choose to rewrite The Sound and the Fury (1929), Light in August (1932), Absalom, Absalom! (1936), Intruder in the Dust (1948), or any Faulkner works more "obviously" engaged with race and racial representation, but As I Lay Dying, the tale of a poor, white family that undertakes an epic journey during a storm in order that they carry out their mother's dying wish to be buried in Jefferson. ${ }^{2}$ Equally, the relationship between canonical text and rewrite must also be reconsidered in the case of Salvage the Bones. Ward's novel openly trades on the canonicity of Faulkner's novel in order to render her protagonists both visible and durable in the face of certain post-Katrina discourses. In The World Republic of Letters, Pascale Casanova examines the extent to which Faulkner's work has influenced and inspired that of writers from marginalized communities, from rural Spain to Algeria to Latin America. According to Casanova, such writers have found Faulkner's work appealing because Faulkner gave "acceptable literary form to the most repugnant realities of the margins of the world" (337). With a single stroke "he wiped out the accumulated backwardness of literatures that hitherto had been excluded from the literary present, which is to say from stylistic modernity" (338). By drawing on As I Lay Dying in Salvage the Bones, Ward similarly asserts the dignity and worth of her characters, those whom neoliberalism would construe as the "waste-products of the American Dream, if not of modernity itself" (Giroux 186).

\section{"The Biopolitics of Disposability" and the "Human Debris" of Hurricane Katrina}

The day before the hurricane makes landfall, the Batistes receive an automated call from the state government issuing an order for "Mandatory 
evacuation....If you choose to stay in your home and have not evacuated by this time, we are not responsible. You have been warned" (Ward 217). Here, non-evacuation is framed in terms of the neoliberal discourse of choice; not evacuating is thus construed as a "bad choice" on the part of the Batistes, rather than an effect of poverty, lack of transportation, and no access to alternative accommodations elsewhere. Indeed, in the aftermath of Hurricane Katrina, then US Senator for Pennsylvania Rick Santorum stated in an interview "that people who did not heed evacuation warnings in the future may need to be penalized" (qtd. in Giroux 176). As Henri Giroux points out, for Santorum, non-evacuees "had become an unwelcome reminder of the state of poverty and racism in the United States, and for that they should be punished" (176). The Batistes do not heed the evacuation warning not because they are irresponsible and negligent, but because they have nowhere to go.

Salvage the Bones, then, writes back to a discursive environment in which neoliberal ideology and racism entered a different kind of "coalition of the willing." As Giroux observes, when Ronald Reagan took office in 1980, the "twin images of the young black male 'gangsta' and his counterpart, the 'welfare queen,' became the primary vehicles for selling the American public on the need to dismantle the welfare state" (172). Indeed, several scholars have argued that "racialized narratives about motherhood" were "key to the neoliberal retrenchment of public support for the poor" in the 1980s and 1990s (Daniel 974-75). As Wendy Brown contends, neoliberalism "figures individuals as rational, calculating creatures whose moral autonomy is measured by their capacity for 'self-care' - the ability to provide for their own needs and service their own ambitions" (42). According to neoliberal logic, then, a teenage single mother is, thus, exemplary of a "mismanaged life" (42). What was made manifest by Hurricane Katrina, for Giroux, were the effects of this systematic assault on the welfare state; in short, the existence of a "new biopolitics"-a "biopolitics of disposability"- that is "organized around the best way to remove or make invisible those individuals and groups who are either seen as a drain or stand in the way of market freedoms, free trade, consumerism, and the neoconservative dream of an American empire" (174-75). It is in this context that we must read Esch's description of herself and her family, after the hurricane, as "human debris in the middle of all of the rest of it" (Ward 237). Rendered "invisible, utterly disposable" by the demands of neoliberalism, the victims of Hurricane Katrina are, paradoxically, made hypervisible through the circulation of the same set of stereotypes instituted twenty-five years previously (Giroux 175).

One of the most infamous examples of this kind of rhetoric was expressed by George Will in a response to (then) Senator Barack Obama's critique of President Bush's lack of empathy for the victims of the hurricane. Will wrote in the Washington Post: 
America's always fast-flowing river of race-obsessing has overflowed its banks....[Obama] might, however, care to note three not-at-all recondite rules for avoiding poverty: Graduate from high school, don't have a baby until you are married, don't marry while you are a teenager. Among people who obey those rules, poverty is minimal....Given that most African Americans are middle class and almost half live outside central cities, and that 76 percent of all births to Louisiana African Americans were to unmarried women, it is a safe surmise that more than 80 percent of African American births in innercity New Orleans - as in some other inner cities - were to women without husbands. That translates into a large and constantly renewed cohort of lightly parented adolescent males, and that translates into chaos in neighborhoods and schools, come rain or come shine.

Will was not alone. As Barbara Ransby demonstrates, black and white conservatives united to scapegoat African American single mothers living in poverty in the stricken areas. Echoing Will, Mona Charen wrote that "[a]mong those [African Americans] who make up the 24.7 percent in poverty, the overwhelming majority are unmarried women and their children," a statement that quite obviously implies that black single mothers are to blame for their own poverty. Similarly, a conference held in 2006 by the conservative Heritage Foundation "placed much of the blame on deficient moral values...and teen pregnancy, which arguably complicated assistance efforts after the hurricane" (Vaught 416). Through her counter-discursive portrayal of an African American single mother and her family and wider community, Ward's novel revises these dominant media representations and participates in a "cultural politics of resistance and hope" that Giroux sees as essential to a broader politics that will provide "a decent education, housing, and health care to all residents of the United States" (Giroux 189). Ward's novel, by channeling Faulkner's, thus restores to rewriting a sense of "revisiting the past in order to change the future" (Plate 391), an aspect of re-visionary fiction that Plate believes has disappeared from contemporary fiction..

\section{"Why does the young boy think his mother is a fish?"}

Two of the major revisions to Faulkner's work that Ward undertakes are those of characterization and narrative voice, both of which facilitate a critique of discourses surrounding the African American family after Hurricane Katrina. The character pairs that correspond least problematically are Vardaman/Junior, Addie/Mama (as absent presences), and Dewey Dell/Esch. Junior claims to "see things" (Ward 185), a detail consistent with Vardaman, who, among other things, sees Darl set fire to Gillespie's barn (Faulkner 198). Similarly, when Vardaman arrives at the Tulls' house on the rainy night of his mother's death, Tull describes him as a "drownded puppy" $(62,63)$, while Junior is "forever the puppy weaned too soon" (Ward 89). Ward's other characters in Salvage the Bones resemble Faulkner's to the extent that they are recognizable as redrawn versions of Faulkner's, but they do not map directly on to those in As I Lay 
Dying. In Faulkner's novel, the Bundrens are atomized: despite the display of family unity they assume in undertaking the journey to Jefferson-Anse is disgruntled that Jewel wants to ride alongside the wagon rather than in it "with her [and those] that sprung from [Addie's] flesh and blood" (Faulkner 93) - almost every member of the family is motivated by selfish reasons for going to Jefferson. When Addie notes of the schoolchildren that she used to teach that "each [has] his and her secret and selfish thought" (155), she might just as easily have been referring to her own family. When they reach Jefferson, Dewey Dell is hoping to procure an abortion, Vardaman a toy train (though he will have to settle for bananas), Cash a graphophone (or "talking machine" [176]), and Anse a new set of teeth. Much of Faulkner's novel, then, is devoted to its characters coming to terms with their separate subjectivities: "an is different from my is," as Vardaman puts it (52).

By contrast, in Salvage the Bones, Ward takes some of the defining physical and personality traits of Faulkner's characters-Darl's clairvoyance; Jewel's devotion to his horse; Cash's methodical thinking and talent for carpentry; Anse's deformities - and redistributes them across and among her own characters. The fluidity that exists between Ward's characters suggests that this is a family unit in which identities overlap, in which cooperation and empathy rather than atomization and selfishness are the distinguishing features. Ward's characterization can thus be read as a strategy of resistance to the pathologizing of the black family-albeit without romanticizing their struggles - that became so pervasive in post-Katrina discourse. For instance, Esch's brother Skeetah alternately evokes Darl, Jewel, and Cash. He is "the odd one, the one that always smells like sweaty fur when all the boys are together, the one the girls probably think stinks" (Ward 33), while Darl is "the one that folks say is queer, lazy, pottering about the place no better than Anse" (Faulkner 22), "the one folks talks about" (99), the one with "queer eyes" (111). Darl's clairvoyance is repeated in Skeetah's: just as Darl knows about Lafe and Dewey Dell (and, indeed, that Jewel was illegitimately conceived $[24,122])$, so Skeetah is aware of Esch's relationship with Manny and guesses that she is pregnant (Ward 47, 86). Skeetah's clairvoyance is further suggested by Esch's claim that her brother, literally, "looks through [her]" (214). On the other hand, his obsession with his dog, China, resonates with Jewel's love for the horse he buys from old Lon Quick. Indeed, while Jewel spends nights working to earn money to buy the horse, Skeetah persuades the local Catholic Church "to pay him to cut the grass and pull weeds at the graveyard" in order to finance the purchase of China's dog food (28-29). Skeetah's "hammering" (20) as he builds a kennel for China's puppies initially recalls Cash's "hammering and sawing" in As I Lay Dying (Faulkner 13). However, when he steals wood that his father has been putting aside to board up the windows of their house in anticipation of the hurricane, the greater concern he shows for the dog, rather than his family, recalls Dewey Dell's admonition that Jewel "is not kin to us 
in caring, not care-kin" (23). Eventually, Jewel is forced to exchange the horse for a team of mules so that the Bundrens can continue on their journey, while Skeetah abandons China in flood water in order to rescue Esch (Ward 235). Furthermore, the delineation of Skeetah as "rigid, as straight as the hammer hanging at his side" in a confrontation with Daddy (105) recalls Faulkner's repeated depictions of Jewel as "rigid" (Faulkner 3, 11, 168, 193).

There are affinities, too, between Randall and Jewel. As Darl observes, Jewel is "a head taller than any of the rest of us" (Faulkner 16). Meanwhile, Randall is also "[t]aller than Daddy" (Ward 2), "taller than all of them" (151). If Jewel is frequently described as rigid, so Randall is "black as iron, rigid as a gate" (151). It is also intimated in the novel that Randall, like Jewel, is not his father's son. Esch wonders "if Daddy is amazed at how this tall machine of a boy came out of him and mama" (180), a thought that is not particularly suggestive until a subsequent exchange that Esch overhears between Randall and Manny. Here, Randall appears to intimate that he is not "blood" to Skeetah, Esch, and Junior. Randall tells Manny:

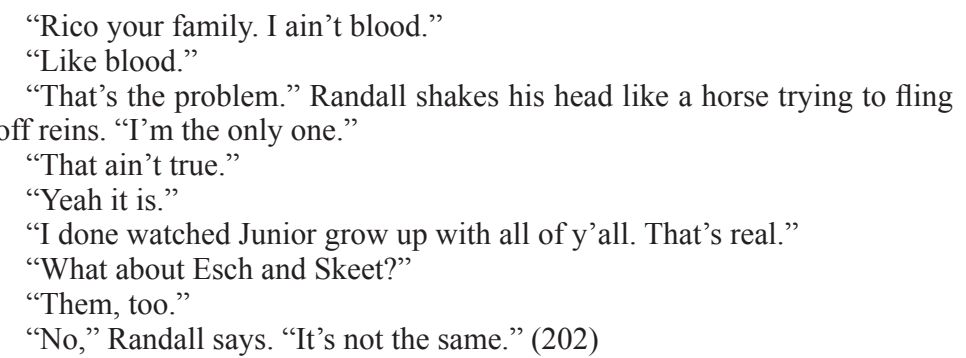

Meanwhile, if Daddy's hands-off approach to parenting recalls that of Faulkner's Anse, his determination to "[fix] up for the hurricane" positions him as more of a Cash than an Anse (Ward 4). The "Thwack, thwack, thwack" of his hammer as he dismantles the chicken coop to add to his supply of wood (109) echoes the "Chuck. Chuck. Chuck" of Cash's adze as he undertakes the task of constructing a coffin for his own mother (Faulkner 4). Moreover, the list of instructions Daddy gives his children in "the ninth day" section of the novel is heavily reminiscent of Cash's first narrative section in As I Lay Dying, in which he describes methodically, in numbered segments, the process of constructing a coffin (Ward 187-93; Faulkner 73). The physical deformity suffered by the hapless Cash also reverberates in Daddy's experience. Cash, who has just recovered from an injury he sustained falling off a church, breaks the same leg while attempting to transport Addie's coffin across the ford. After the family decides to set his bones using cement, it is clear that this "misfortunate man" will have to have his leg amputated (Faulkner 149). In Salvage the Bones, Daddy was involved in an accident with his dump truck that resulted in him 
receiving "disability checks" (90). Years later, as Daddy and Randall attempt to dismantle the chicken coop, there is an accident involving the same dump truck in which Daddy's "middle, ring, and pinkie finger on his left hand are sheared off clean" (Ward 129-30).

The fluidity that exists between the characters in terms of physical and personality features is reinforced by the novel's assertion of the Batistes as a united group in other ways. In As I Lay Dying, the close relationship that exists between Dewey Dell and Darl - Cash observes that "they kind of knowed things betwixt them" (Faulkner 220) - is undone at the novel's end by Dewey Dell's desperate fear that Darl will reveal that she is pregnant. Cash suspects that she tells Gillespie who burned his barn and, therefore, that she is responsible for Darl being committed to an asylum. By contrast, Salvage the Bones emphasizes, throughout and to its conclusion, the intimacy that exists between Skeetah and Esch — certainly — but also between Randall and Esch. In the course of preparing for the hurricane, Randall reveals a "softness" that Esch has never before seen in her brother, except in his baby pictures (Ward 206). In As I Lay Dying, when the orderlies come to take Darl away, Dewey Dell "jump[s] on him like a wild cat so that one of the fellows had to quit and hold her and her scratching and clawing at him like a wild cat" (Faulkner 220). In Salvage the Bones, Esch instead subjects the father of her child, Manny — rather than her brother - to a similar attack, raking her "fingernails across his face, leav[ing] pink scratches that turn red, fill with blood" (Ward 204). In Ward's novel, the teenage girl's brother does indeed reveal that his sister is pregnant, but he does so in order to protect Esch when the family tries to escape rising floodwater in their own home to take refuge in Mother Lizbeth's nearby house (234). Furthermore, her father reacts to the news with some sensitivity and concern, looking at her with "a glance [that] was so soft, so tentative and tender" (243). After the hurricane subsides, Esch confides to Big Henry, an honorary member of the family, her concern that her baby "don't have a daddy," to which Big Henry responds "You wrong.... This baby got plenty daddies" (255), a response that openly contradicts the kind of stereotype propounded by commentators such as Will in the aftermath of Katrina. At the end of the novel, the siblings and Big Henry comfort Skeetah, who is desperate for China to be restored to him. Esch's description of their mutual responsibility for one another-"Randall will watch Junior and Big Henry will watch me and I will watch Skeetah and Skeetah will watch none of us" (258) - contrasts dramatically with the end of Faulkner's novel, in which the remaining siblings, absent Darl, are shocked by their father's sudden remarriage and their introduction to the new "Mrs. Bundren" (Faulkner 242).

The second substantial revision Ward makes to Faulkner's novel is reducing his fifteen narrators to the single narrative voice of Esch. In As I Lay Dying, the multiple perspectives provided by Faulkner's fifteen narrators are consistent with his modernist assault on and experimentation with that staple 
of realist fiction, the omniscient narrator. Nineteen of the novel's fifty-nine sections are narrated by Darl, whose perspective comes closest to omniscience: he sees and narrates events at which he was not present, such as Addie's deathbed scene (43-48). Significantly, he is also the character that goes mad at the end of the novel. In other words, As I Lay Dying sounds the death knell of the omniscient narrator, ousting Darl from a position of near omniscience to one in which he refers to himself in the third person: "Darl has gone to Jackson. They put him on the train, laughing, down the long car laughing, the heads turning like the heads of owls when he passed" (235). For Faulkner, then, multiple narrative perspectives are the vehicle for his elucidation of the limitations of an omniscient narrator. In Salvage the Bones, however, Ward is less concerned with formal experimentation than she is with the single perspective of a first-person narrator, Esch. Reworking the centrifugal direction of Faulkner's multiple narrators, Ward recenters the narrative around Salvage the Bones's pregnant teenager. This contrasts with As I Lay Dying, in which Addie Bundren, the dead mother, is the novel's "centre that does not hold." In other words, Salvage the Bones deliberately reorders the "chaos" of Faulkner's multiple perspectives, a formal gesture that writes back to the media narratives that attribute "chaos in neighborhoods and schools" (Will) to the pervasiveness of African American single motherhood in contemporary America.

\section{"The Voice of the Waste and Mournful Water"}

The most obvious and significant character parallels are those between Esch and Dewey Dell, the pregnant teenagers, and between Mama and Addie, the dead mothers. Dewey Dell and Lafe succumb to their sexual desire with "the woods getting closer and closer" (Faulkner 23) while Manny surprises Esch "in the woods while I was looking for Junior and grabbed me, knew my girl heart" (Ward 57). Like Dewey Dell, Esch struggles to comprehend the extent to which the integrity of her body has been threatened by sexual intercourse and the resulting pregnancy. Dewey Dell feels "like a wet seed wild in the hot blind earth" (Faulkner 58), while Esch, who is distraught to witness Manny, the father of her child, flirting with another girl, "wishes she could reach inside of me and pull out my heart and that tiny wet seed that will become the baby" (Ward 122). Darl imagines Dewey Dell asking Doctor Peabody to perform an abortion on her, hearing his sister reflect that "if you [Peabody] just would then I could tell you and then nobody would have to know it except you and me and Darl" (Faulkner 48), while Esch also contemplates an abortion in terms that explicitly recall Faulkner's distinctive style: "If I took care of it, he [Manny] would never know, I think, never know, and then maybe it would give him time. Time to what? I push. Be different. Love me" (Ward 103). One of the starkest revelations of Ward's novel is how similar (and few) Esch's options are when compared to those of Dewey Dell, a (white) character written some eighty years previously. In Mottson, Dewey Dell's euphemistic enquiries 
about procuring an abortion are batted away by a self-righteous pharmacist. In Jefferson, she is exploited by Skeet MacGowan, who promises to give her an abortifacient in exchange for sex. In Salvage the Bones, Esch considers inducing abortion by taking several birth control pills: "Only thing I wouldn't be able to find is the birth control pills; I've never had a prescription, wouldn't have money to get them if I did, don't have any girlfriends to ask for some, and have never been to the Health Department" (102). She soon realizes that her options "narrow to none" (103).

It might seem peculiar that a black Southern woman would draw upon the work of a white Southern man in order to inform her representation of pregnancy and maternity among her African American female characters. Indeed, Ward's portrayal of motherhood initially appears quite different to that of Faulkner. Addie's professed indifference as a mother contrasts with Mama, whom Esch remembers as very loving. Esch recalls the death of her grandmother, Mama's mother, and how she "clung like a monkey to Mama, my legs and arms wrapped around her softness." After Mama dies, "there was no one left for [her] to hold on to" (Ward 59). Addie admits that, because she gives birth to a child (Jewel) who is not her husband's, she has Dewey Dell "to negative Jewel" and gives Anse Vardaman "to replace the child I had robbed him of" (Faulkner 162). By contrast, Mama professes joy at her pregnancy with Junior, eight to ten years after the births of Randall, Skeetah, and Esch, and calls it "a happy accident" (Ward 217). Yet it is Faulkner's productive ambivalence regarding sexuality, maternity, and motherhood that appeals to Ward. ${ }^{3}$ Presumably, she would in no way endorse Will's explanation of poverty among African Americans in the US South, yet neither does she portray Esch's situation as desirable. She wishes to acknowledge the terrible conditions under which Esch lives without completely divesting her of her agency. Therefore, it is through the overlapping pairings of Esch/Dewey Dell and Mama/Addie that the relationship between motherhood, reproduction, and waste is most emphatically drawn by Ward. In both novels, motherhood is put forth as an ambivalent and compromised form of power that combats the relegation of the maternal body to that of literal (in Faulkner's novel) or discursive (in Ward's) waste.

After all, As I Lay Dying traces Addie's thwarted resistance to motherhood and, after she dies, the gradual decomposition of her maternal body as the Bundrens undertake their journey to Jefferson. After she has Darl, Addie asks Anse "to promise to take [her] back to Jefferson when [she dies]," to which Anse replies "Nonsense...you and me aint nigh done chapping yet, with just two" (Faulkner 159). Thus, when Cora describes a dying Addie, at the beginning of the novel, noting her face "wasted away so that the bones draw just under the skin in white lines" and her eyes "like two candles when you watch them gutter down into the sockets of iron candle-sticks" (7), the reader cannot help but associate Addie's exhausted and expiring — "wasted"—-body 
with her many years of childbearing and rearing. When the family embarks on their journey, Cash warns that in a couple of days, the body will "be smelling" (96). Indeed, by the time the Bundrens reach Samson's, their host for the night imagines that he can smell the body, "even when I knowed I couldn't" (104). As it turns out, Samson is correct: after the Bundrens have departed, he discovers a buzzard in his barn who has been attracted there by Addie's rotting corpse. Further along, Armstid attributes his first sighting of a buzzard to the damp weather conditions but as more and more of them come "circling and circling for everybody in the county to see what was in my barn," he realizes that he, too, can "smell [the corpse] in the field a mile away" (172). Meanwhile, Armstid reports seeing Vardaman "chasing them buzzards all day in the hot sun until he was nigh as crazy as the rest of them" (178).

Yet, there are moments, too, in which Addie's maternal body does manage to resist its disintegration into waste and asserts, instead, the power of motherhood, even after death. This is most apparent in those passages in which a connection is forged between trees or wood (especially the novel's wooden bridges), water, and maternity. In As I Lay Dying, trees are-initially, at least - associated with stasis. Anse justifies his unwillingness to move by claiming that when God "aims for something to be always a-moving, $\mathrm{He}$ makes it long ways, like a road or a horse or a wagon." But "when He aims for something to stay put, He makes it up-and-down ways, like a tree or a man" (31). Meanwhile, Peabody observes that "the Lord made the mistake of giving trees roots and giving the Anse Bundrens He makes feet and legs. If He'd just swapped them, there wouldn't ever be a worry about this country being deforested someday. Or any other country" (38). Just before it begins to rain, a connection is forged between trees, water, and maternity when Darl describes trees, "motionless, [that] are ruffled out to the last twig, swollen, increased as though quick with young" (68).

However, the ability of the storm to uproot trees and wash away bridges suggests a form of power that belies the trees' stasis. In the novel, the storm comes to represent a pregnant woman with the uprooted trees symbolizing the children she detaches from herself during labor. After Addie dies and the storm has begun in earnest, the menfolk discuss the washing away of a local bridge, one of them noting that it must have been completed in 1888 because Doctor Peabody, traveling to deliver this man's child, was the first to cross it. Peabody jokes that "If [he'd] crossed it every time [Billy's wife] littered since, it'd a been wore out long before this" (78). In this passage, an explicit link is established between the "wore out" bridge and the "wore out" mother who has "littered" so many children since 1888. However, the association of washed out bridges with motherhood is also suggestive of power. When Tull remarks that "[o]ne part of you knowed it was just water, the same thing that had been running under this same bridge for a long time, yet when them logs would come spewing up outen it, you were not surprised, like they was a part 
of the water, of the waiting and the threat" (124), his observation speaks both to the banality and perceived monstrousness of childbirth. Meanwhile, Darl also reflects on the stirrings of "the thick dark current," noting that it is as though "just beneath the surface something huge and alive waked for a moment of lazy alertness out of and into light slumber again" (127). When he describes the current talking up to them "in a murmur become ceaseless and myriad," the language explicitly anticipates his subsequent imagining of his dead mother talking "in little bursts of secret and murmurous bubbling" (195). Above the surface of the water stand "trees, cane, vines - rootless, severed from the earth, spectral above a scene of immense yet circumscribed desolation filled with the voice of the waste and mournful water" (127). The voice he imagines he hears may be one of "waste," but it is also one of immense power.

In As I Lay Dying, then, the wasted body of the poor, white Southern mother is invested with a compensatory power. Doreen Fowler's influential psychoanalytic-feminist reading of Faulkner's novel even goes so far as to frame Addie's request that she be buried in Jefferson, which propels her family on their disastrous journey, as a form of "Mother's revenge" (113). In Salvage the Bones, the relationship between waste, poverty, and motherhood engages with the contemporaneous discourse in which African American single mothers are consigned to the category of waste because of their "improper" conduct as neoliberal subjects. Throughout the novel, pregnancy and maternity are linked to rain, floods, storms, and trees, a correlation that also vacillates between associations of passivity and victimhood, on one hand, and power and agency on the other. Storm metaphors are deployed to convey Esch's feelings of powerlessness regarding her pregnancy. When she takes a pregnancy test, the "terrible truth" is conveyed to her by "[c]olor wash[ing] across the stick like a curtain of rain" (Ward 36). When she describes the fetus being nourished by the food she consumes, she imagines "the food turning to mush, sliding down my throat, through my body like water through a storm drain to pool in my stomach" (41). The baby "sits like a water balloon in [her] stomach, mak[ing her] feel set to bursting" (45). Her belly feels "like a bowl sloshing with water" (207). What she carries in her stomach is "relentless" (205); similarly, the storm's rain bears "relentlessly...down on the house" (225). At one point during the storm, Esch thinks she is miscarrying ("Why are my shorts wet? Is it gone? Am I bleeding?") but soon realizes that water is, in fact, coming into the house (226). Similarly, Mama's pregnancies and experiences of childbirth also become associated with hurricanes. Esch recalls Hurricane Elaine in 1999, when her mother is "big with Junior" (217). Esch puts her ear on Mama's stomach and hears "the watery swish of Junior inside her" (217). While the storm rages outside, Mama "talk[s] back to Elaine. Talked over the storm. Pulled us in in the midst of it, kept us safe" (218). But Mama's ability to "spell [the storm] harmless" is compromised by the reader's knowledge that she died in childbirth (219). Reminiscent of Addie's exhausted and haggard 
body, the sound of "the pines, the thin trees bending with the storm, bending almost to breaking" reminds Esch of "Mama's moans [in childbirth], of those bowing pines, of a body that can no longer hold itself together, of something on the verge of breaking" (222-23).

At the same time, as well as positioning Esch as passive victim of the hurricane, Salvage the Bones constructs the storm as a vengeful mother that wreaks havoc on her children. As the Batistes await the storm, Esch notes that it has not rained for weeks: "The shower we needed was out in the Gulf, held like a tired, hungry child by the storm forming there" (15). Katrina's wrath is inflicted on the landscape in the form of "the flailing wind that lashes," the rain, "which stings like stones," causing "trees and branches [to break, to pop] like firecrackers in an endless crackle of explosions" (230-31). After the storm has ended, the family sees the effects of Katrina on their environment, noting that the storm had "plucked the trees like grass and scattered them," rendering them "all broken, all crumbled" (241-42). Ultimately, Katrina is imagined as "the mother that swept into the Gulf and slaughtered":

a murderous mother who cut us to the bone but left us alive, left us naked and bewildered as wrinkled newborn babies, as blind puppies, as sun-starved newly hatched baby snakes....Katrina is the mother we will remember until the next mother with large, merciless hands, committed to blood, comes. (255)

However, Salvage the Bones does not endorse an unproblematic notion of motherly power and revenge. After all, through the concatenation of associations between the storm, trees, and destructive motherhood, the novel underlines that it is those who are already vulnerable, the "wrinkled newborn babies," who suffer its effects most drastically.

\section{"Something that will help me to tell the story"}

As I Lay Dying blurs the boundary between trees, human bodies, and waste when referring to the maternal body. The deceased Addie is, for Doctor Peabody, "no more than a bundle of rotten sticks" (Faulkner 40), while Darl refers to "the handful of rotten bones that Addie Bundren left" (44). A similar connection is made in Salvage the Bones; the morning after the hurricane, Esch refers to herself and her family as "a pile of wet, cold branches, human debris in the middle of all the rest of it" (Ward 237). Faulkner's text is radically repurposed by Ward, then, not simply in a metaphorical sense but also to the extent that it foregrounds as politicized gestures the relationships between garbage; recycling, in which an object is reused for a purpose different from its original function; and salvaging, in which an item is reused for the same purpose. The Pit, where the Batistes live, is a desolate landscape, their house "nearly invisible under the oaks and behind the rubbish, lopsided" (116), a space of "discarded plastic garbage cans, detached fenders" (126). Their 
"refuse-laden yard" is filled with detritus: "refrigerators rusted so that they look like deviled eggs sprinkled with paprika, pieces of engines, a washing machine so old it has an arm that swished the clothes around and looks like a handheld cake mixer" $(18,89)$. Yet, as a consequence of the financial hardship in which they live, the Batistes salvage and reuse as much as possible, thus calling into question the status of that which Esch herself calls "rubbish," "refuse," and "detritus."

For instance, Esch admires Skeetah's ability to "take rotten boards and make them a kennel, make a squirrel barbecue, make ripped tile a floor" (75). In contrast with Faulkner's Vardaman, who has to wait until Christmas for his coveted toy train to be delivered, Ward's Junior makes do with a "dull black bike [that] wobbles from side to side with each pedal" - too small for him to ride - that he "found" (116). Equally, Daddy dismantles the chicken coop so as to generate a wood supply to board up the windows of their home (125). In the most macabre and extreme example of potential recycling, Skeetah suggests that he and his siblings search for the three fingers that have been shorn from his father's hand after an accident: "That's free protein," he notes. "We could feed them to China" (187). Meanwhile, Esch's grandmother's house is the site of the most insistent salvaging and recycling. As the family prepares for the hurricane, they visit Mother Lizbeth's house and "pick at the house like mostly eaten leftovers" (58). Skeetah seeks out some linoleum to cover the dirt floor in the shed where he keeps his dogs; Daddy hunts for some pieces of plywood. Indeed, the house is "a drying animal skeleton, everything inside that was evidence of a living salvaged over the years" (58). After Mother Lizbeth died, they took "couch by chair by picture by dish until there was nothing left" (58). It is significant that it is precisely this house, which is situated on a slight hill, to which the family is able to retreat when they are forced to abandon their own house due to rising flood waters. This apparently pointless "hollow carcass" (231), comprising only "the patchy remains of Mother Lizbeth's rotting house" (10), provides them with shelter when they have nowhere else to go (231).

After the hurricane, Esch, Randall, Junior, and Big Henry drive to St. Catherine to determine how the storm has affected it and to see if they can salvage anything. In one part of town, there are "no foragers...picking through the rubble. What could be salvaged? What hasn't been buried or swept out to sea?" (252). Esch searches amid the rubble for something to take back to Skeetah, "something that will help me tell him the story of what we found" (254). But there is "nothing here but broken bottles, smashed signs, splintered wood, so much garbage" (254). However, she gathers up two shards of glass and a pink brick stone which she subsequently ties with string and hangs above her bed, "so that they will flash in the dark and tell the story of Katrina" (255). Whereas some post-Katrina discourses would frame the Batistes themselves as "so much garbage," Ward's emphasis on both recycling and salvaging constitutes a powerful counter-discursive gesture. The recycling and salvaging 
of elements of Faulkner's As I Lay Dying are, in a similar way, the "something that [helps]" Ward tell the story of one poor black family's experience of Hurricane Katrina. Addie Bundren may only have left behind a "handful of rotten old bones" but Ward encourages readers to "salvage" those bones (Faulkner 44). In so doing, she engages in a new form of re-visionary fiction that engages more emphatically than previous models of rewriting in a critique of contemporary sociopolitical realities.

\section{UNIVERSITY OF EXETER}

\section{NOTES}

1 There are several further connections between the two novels that, due to space constraints, are not discussed here. Future analyses might compare two set pieces: the first, from As I Lay Dying, in which the Bundrens arrive at Jefferson and the sorry state (and stench) of their wagon elicits a comment from one of "[t]hree negroes walk[ing] beside the road" ahead of them (Faulkner 212); the second, in Salvage the Bones, in which "three negroes" (Esch, Skeetah, and Big Henry) come upon a car accident involving a white couple (Ward 30-35). Future readers might also productively compare Vardaman's infamous equation of his mother with a dead fish (Faulkner 74) and Mama's killing of a baby shark, which she "coaxe[s]" to death (Ward 85).

${ }^{2}$ Werner theorizes the influence of Faulkner on African American writers, arguing that his obsession with framing African American characters in terms of a "narrative of endurance"- most famously embodied by Dilsey in The Sound and the Fury (1929)— “severely limits Faulkner's direct influence on Afro-American writers" (29). However, Werner's discussion is itself restricted to the representation of African American characters in Faulkner's work. In fact, the appeal of As I Lay Dying to African American writers is borne out by the fact that Suzan-Lori Parks's only novel, Getting Mother's Body (2003), is also a rewrite of Faulkner's novel. In Parks's novel, it is 1963 and pregnant teenager Billy Beede, along with assorted family members and hangers-on, embarks on a road trip from Lincoln, Texas, to LaJunta, Arizona, to exhume the body of her dead mother, Willa Mae.

${ }^{3}$ Motherhood and maternity in As I Lay Dying have long been topics of interest to feminist scholars, particularly those writing from a psychoanalytic perspective. See Fowler and see Clarke. See also Holcombe's fascinating historicist reading.

\section{WORKS CITED}

Brockes, Emma. "Jesmyn Ward: 'I wanted to write about the people of the south." Guardian 1 Dec. 2011. Web. 24 April 2012.

Brown, Wendy. Edgework: Critical Essays on Knowledge and Politics. Princeton: Princeton UP, 2005.

Baudrillard, Jean. The Illusion of the End. Trans. Chris Turner. Stanford: Stanford UP, 1992.

Casanova, Pascale. The World Republic of Letters. Trans. M. B. DeBevoise. Cambridge: Harvard UP, 2004.

Charen, Mona. "No more marches." Townhall.com. 14 Oct. 2005. Web. 17 May 2012.

Clarke, Deborah. Robbing the Mother: Women in Faulkner. Jackson: UP of Mississippi, 1994.

Daniel, Clare. "“Taming the Media Monster': Teen Pregnancy and the Neoliberal safety (Inter) Net.” Signs 39.4 (2014): 973-98.

Faulkner, William. As I Lay Dying. 1930. New York: Vintage, 1987. 
Fowler, Doreen. "Matricide and the Mother's Revenge: As I Lay Dying." Faulkner Journal 4.1-2 (1988): 113-25.

Giroux, Henri. "Reading Hurricane Katrina: Race, Class and the Biopolitics of Disposability." College Literature 33.3 (2006): 171-96.

Gray, Richard. A Web of Words: The Great Dialogue of Southern Literature. Athens: U of Georgia $\mathrm{P}, 2007$.

Gwynn, Frederick L., and Joseph L. Blotner, eds. Faulkner in the University: Class Conferences at the University of Virginia, 1957-1958. Charlottesville: U of Virginia P, 1959.

Holcombe, Heather E. "Faulkner on Feminine Hygiene, or, How Margaret Sanger Sold Dewey Dell a Bad Abortion." Modern Fiction Studies 57.2 (2011): 203-29.

Hutcheon, Linda. A Poetics of Postmodernism: History, Theory, Fiction. London: Routledge, 2000.

—. The Politics of Postmodernism. London: Routledge, 1991.

Jameson, Fredric. Postmodernism, or, the Cultural Logic of Late Capitalism. Durham: Duke UP, 1991.

Moraru, Christian. Rewriting: Postmodern Narrative and Cultural Critique in the Age of Cloning. Albany: State U of New York P, 2001.

Parks, Suzan-Lori. Getting Mother's Body. 2003. New York: Random House, 2004.

Plate, Liedeke. "Remembering the Future; or, Whatever Happened to Re-vision?" Signs 33.2 (2008): 389-411.

Ransby, Barbara. "Katrina, Black Women, and the Deadly Discourse on Black Poverty in America." Du Bois Review 3.1 (2006): 215-22.

Sanders, Julie. Adaptation and Appropriation. Abingdon: Routledge, 2006.

Vaught, Seneca. "An 'Act of God': Race, Religion, and Policy in the Wake of Hurricane Katrina." Souls: A Critical Journal of Black Politics, Culture, and Society 11.4 (2009): 408-21.

Ward, Jesmyn. Salvage the Bones. New York: Bloomsbury, 2011.

Werner, Craig Hansen. Playing the Changes: From Afro-Modernism to the Jazz Impulse. Urbana: U of Illinois P, 1994.

Widdowson, Peter. "Writing Back: Contemporary Re-Visionary Fiction." Textual Practice 20.3 (2006): 491-507.

Will, George F. “A poverty of thought.” Washington Post 13 Sept. 2005. Web. 18 May 2012. 